\title{
The ultimate limits of crop production
}

\author{
By J. N. BLACK, Department of Forestry and Natural Resources, University of \\ Edinburgh
}

\section{Introduction}

Although one of the most important aims of research into agricultural and allied problems has always been the recognition and elimination of factors limiting the yield of crop plants, little has been done to codify the basic ecological nexus in which they operate. In this country, emphasis has traditionally been placed on the role of soil fertility in restricting yield, and much time and effort has been devoted to the amelioration of soil conditions and the provision of nutrient elements in the form of fertilizers. A second major field of study has been the genetic background of crop plants and the deliberate creation of more highly adapted varieties; a great deal, too, has to be done to reduce losses in yield caused by pests and diseases.

Nevertheless, edaphic factors such as soil structure and nutrient status interact with the genetic make-up of a variety within a closely interrelated mesh of climatic factors. For many years, agricultural climatology in this country seemed to be concerned primarily with temperature and the frost-free period, but the recent studies of Penman (e.g. 1958) have brought about a widespread realization that, over much of this country, moisture deficiencies have hitherto unsuspected effects in controlling yields. Although we have now come to accept this as being beyond question, the suggestion say 25 years ago that in south-east England there was a shortage of soil moisture in 9 years out of ro would have been greeted with scepticism, if not with levity. In general terms, the importance of exposure to wind and the beneficial effects of shelter have long been understood, although they have never been examined in detail.

To a greater or lesser extent, most of these conditions tending to limit the yield of crops and pastures may be mitigated: moisture deficiency by irrigation, nutrient deficiencies by fertilizers, exposure by shelter, and so on. Protection against frosts and periods of low temperature may be obtained in small areas where this is economically attractive. Even so, few people have asked themselves the question: if it were possible to remove all these factors acting to maintain yields at a low level, what would then determine yield and what might the yield then be?

This is not an idle question since, as Nichiporovich (1954) has pointed out, a knowledge of the theoretical maximum yield may emphasize by how much the yield obtainable at present by the best agronomic techniques falls below that which could be achieved. Furthermore, by knowing the potential yield, the significance of increases resulting from improved practices may be assessed; an increase in yield of $10 \%$ may, for instance, be economically desirable, but may be found to be only a small fraction of the total increase possible. An assessment of the ultimate limits to yield, therefore, may provide a yardstick with which to measure the efficiency of an agricultural system and the progress of improvements in techniques (Black \& Watson, I960). 


\section{Factors controlling yield}

Within the last 1o or 12 years, a number of studies have shown that when other factors are eliminated, the ultimate limits to production are set by the amount of solar radiation incident upon the crop. Four of these studies may be taken to illustrate this point. Donald (195I) grew swards of subterranean clover (Trifolium subterraneum L.) at a wide range of densities of plants/unit area, and noted that yield did not increase when densities exceeded about I 500 plants $/ \mathrm{m}^{2}$. He concluded that if water and nutrients are in adequate supply, the ceiling yield will be determined by competition for light ... When light and light only has become the limiting factor governing growth per unit area, the species has achieved the maximum production of which it is genetically capable'. This implied that for any environment there must be a 'ceiling yield' set by the amount of light energy available: in Canberra, ACT, where Donald was working, the ceiling yield was $93 \circ \mathrm{g} / \mathrm{m}^{2}$ (9.3 metric tons/hectare), which corresponded well to the maximum yields recorded in other ungrazed swards of subterranean clover grown in the same area during the previous 4 years.

Donald's paper shows clearly the agronomic implications of the factors controlling yield: given adequate water and nutrients, the upper limit of yield is reached when the plant population is sufficient to exploit the light energy available. A similar view, though reached in a different way, was put forward by Blackman \& Black (1959). They recognized that the net assimilation rate (that is, the dry weight increase per unit leaf area) of plants fell as the density of planting - and, hence, the mutual shadingincreased. An examination of growth rates of a number of species growing without self shading showed that radiation limited growth rates even at the height of summer; in field crops with a high degree of self shading, yield would thus be expected to be limited by the light available. They noted that optimal utilization of solar energy depended on maximum absorption by the leaves, and that where temperature, water and nutrients were adequate dry-matter production would be limited by solar radiation and leaf area-essentially the same conclusion as had earlier been put forward by Donald. A further section of their paper calculated the efficiency of utilization of light energy (the percentage of incoming light energy converted into chemical energy and stored in the plant) for a number of agricultural and other crops and showed that, though for short periods efficiencies of $4^{-10} \%$ could be attained, for the whole year efficiencies of $2-3 \%$ were more likely.

Both of these studies were based on experimental data from plants or plant communities. It is appropriate now to consider two other examples of the limiting role of solar radiation, which are based on theoretical considerations.

Bonner (1962) assumed that water, nutrients, temperature and pests were not limiting, and noted that in these circumstances the limiting factor was the efficiency of the photosynthetic system. He then calculated photosynthetic efficiency by assuming that Io quanta were required for the reduction of each molecule of $\mathrm{CO}_{2}$, equivalent to $520 \mathrm{kcal}$. Since the reduction of each molecule of $\mathrm{CO}_{2}$ in photosynthesis stores only $105 \mathrm{kcal}$, the maximum photosynthetic efficiency is $20 \%$. As light intensities increase from low values, the photosynthetic process becomes light- 
saturated: this may occur at intensities of $10-20 \%$ of full daylight. A single leaf absorbs $80 \%$ daylight; $20 \%$ of this is used at an efficiency of $20 \%$; thus the overall efficiency cannot exceed $5 \%$. Light transmitted by the upper leaves of a crop is absorbed by lower leaves, the efficiency of which is high, but nevertheless the 'wasteful' absorption by upper leaves is the main reason for low efficiencies in the field. High photosynthetic efficiencies can be obtained in low light intensities, but with increasing intensities the yield/unit ground area rises.

Loomis \& Williams ( 1963 ) also approached this problem from a theoretical standpoint. They argued that, assuming that ro quanta are required for the reduction of $\mathrm{I}$ molecule of $\mathrm{CO}_{2}$, and knowing the number of quanta in the visible region of the spectrum, the potential productivity of a well-developed crop canopy can be calculated as $7 \mathrm{I} \mathrm{g} / \mathrm{m}^{2}$ day with $500 \mathrm{cal} / \mathrm{cm}^{2}$ day solar radiation, typical of the summer in California where they worked. This calculation assumes average albedo and $10 \%$ inactive absorption by non-photosynthetic pigments, and, a more important assumption, that respiration losses are equal to $33 \%$ of the total photosynthesis. This value of $7 \mathrm{I} \mathrm{g} / \mathrm{m}^{2}$ day can be increased to 77 when the $8 \%$ of inorganic material in the plant is taken into consideration, and this value gives a photosynthetic efficiency of $5.3 \%$ of the total solar radiation and $12 \%$ of the energy in the visible waveband.

A productivity of $77 \mathrm{~g} / \mathrm{m}^{2}$ day very greatly exceeds the rates of dry-matter production quoted by Blackman \& Black (I959), which, for a number of crops, fall between 20 and $30 \mathrm{~g} / \mathrm{m}^{2}$ day with a higher value of 38 for sugar-cane in Hawaii, from the data of Borden (1945). Loomis \& Williams (1963) quote some further values in the same range, but list also a value of $5 \mathrm{I} \mathrm{g} / \mathrm{m}^{2}$ day obtained by Sumner for Sudan-grass in midsummer in California, where radiation is very high. From Bonner's (1962) calculations it seems that values in excess of $20 \mathrm{~g} / \mathrm{m}^{2}$ day are not likely, and there is little doubt that both this figure, and the maximum photosynthetic efficiency of $5 \%$ given by him, are too low. Bonner and Loomis \& Williams agree, however, that the overall inefficiency in the utilization of solar energy can be ascribed to the capacity of the photosynthetic system, the amount and disposition of the leaf system and the availability of $\mathrm{CO}_{2}$. It may be added here that one of the most elusive quantities in crop physiology is the proportion of the gross photosynthesis lost by respiration.

\section{Leaf area and productivity}

From all these lines of investigation it may be concluded that there is a marked association between solar energy and productivity. Nevertheless, the incoming solar energy can only be utilized to the greatest possible extent when the leaf area is sufficient for complete absorption. Therefore for a full understanding of the factors controlling the productivity of plant communities it is necessary to know firstly how growth rate varies with changes in the total leaf area of the community at any one level of solar radiation, and secondly how this relationship varies with changes in the radiation. For the sake of simplicity, we may examine the growth of a pasture sward, the growth of which is not complicated by the development of specialized organs such as grain, tubers or roots: in a pasture the 'economic' yield is more nearly similar to the 'biological' yield (see Nichiporovich, 1954). 
The importance of the total area of leaf on a given area of soil was probably first elaborated by Boysen Jensen (e.g. 1932) in his studies of plant growth in Denmark, and his work was taken up after the war in Japan by Monsi \& Saeki (1953) and considerably developed. Nevertheless, the starting point for much of the recent work was a paper by Watson (1947), in which he wrote: 'The measure of leaf area which is relevant to the comparison of agricultural yields, that is, of the weights of different crops produced per unit area of land, is the leaf area per unit area of land, which it is proposed to call the Leaf Area Index'. This measure of leaf area is particularly useful as it gives a characteristic of the crop as a whole, and is independent of the number of plants or the leaf area of an individual plant.

The first applications of the concept of leaf area index (L) to the growth of pasture swards were made in New Zealand (Brougham, r956) and Australia (Davidson \& Donald, 1958), and summarized by Donald \& Black (1958). It was suggested that as $\mathrm{L}$ increases from very low values at the beginning of the growing season there is a concomitant increase in the proportion of the incident solar energy absorbed by the sward and, as a result, an increase in the rate of dry-weight production. Eventually a value of $\mathrm{L}$ is reached at which all the incident solar energy is absorbed by the sward; at this value of $\mathrm{L}$, the productivity of the sward is maximal. This value of $\mathrm{L}$ may be designated the optimal leaf area index, $\mathrm{L}_{\mathrm{opt}}$, and the maximal value of the crop growth rate ( $\mathrm{C}$, the dry-weight increase per unit ground area per unit time) as $\mathrm{C}_{\max }$, following the terminology proposed later (Black, I963).

However, $\mathrm{L}$ continues to increase after $\mathrm{L}_{\mathrm{opt}}$ is attained, and, since by definition all incoming light energy is already absorbed, an increasing proportion of the leaf tissue at the bottom of the sward grows in light intensities below the compensation point: it is not unusual to find that the lower half or even two-thirds of a dense clover pasture is maintained in light intensities too low to be measured with a photocell. Such leaf tissue cannot contribute to the photosynthesis of the sward; since respiratory loss continues, $\mathrm{C}$ falls below $\mathrm{C}_{\max }$. This was shown for both sugar-beet and kale by Watson (1958) and, more recently, for the oil palm by Rees (1963) and for rice by Kanda \& Sato (1963), and is evidently of general significance. At some high value of $\mathrm{L}$, the photosynthesis of the illuminated leaves may be expected to balance the respiration of the whole sward and $\mathrm{C}$ becomes zero. At some extremely high (and probably temporary) values of $\mathrm{L}$, negative values of $\mathrm{C}$ have been recorded (Black, rg63). It is likely that increasing respiration rate is not of itself sufficient to account for the very marked reductions in $\mathrm{C}$ at high values of $\mathrm{L}$; probably increased senescence and loss of leaves are also involved. Furthermore, the role of the root system in this relationship of $\mathrm{L}$ and $\mathrm{C}$ has not yet been fully described.

The analysis thus far has not taken into account growth at different levels of solar radiation. In I96I two papers appeared in which $L_{0 p t}$ was shown to vary with solar radiation (Stern \& Donald, I96r; Takeda, I96r). It was, indeed, recognized that such a relationship was to be expected, since as radiation increased a greater leaf surface would be required for complete absorption, but up to that time no quantitative relationship based on experimental data had been formulated.

Extended confirmation of this relationship was given by Black (1963) for swards of 
subterranean clover. It was shown that as solar radiation increased, so too did $\mathrm{L}_{\mathrm{opt}}$ and $\mathrm{C}_{\max }$. A family of curves for the relationship between $\mathrm{C}$ and $\mathrm{L}$ at a number of levels of solar radiation were obtained and the diagram from that paper is reproduced in Fig. I. Information on the way in which the swards were grown and the curves derived may be obtained from the original paper.

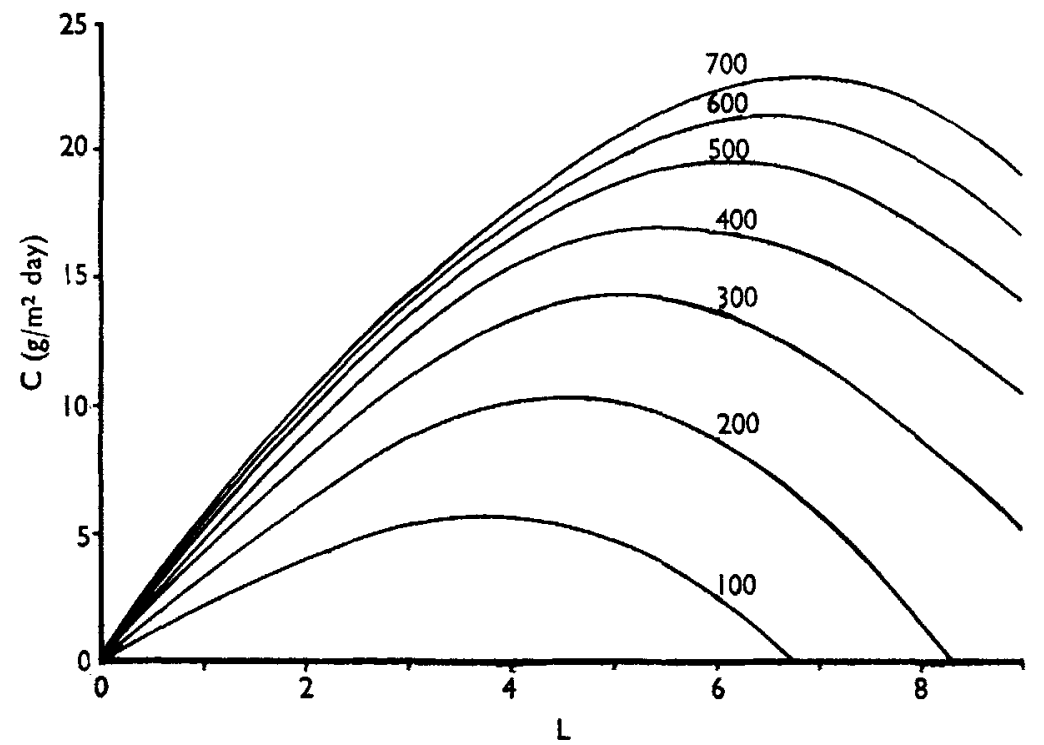

Fig. I. The relationship of crop growth rate (C) and leaf area index $(\mathrm{L})$ at a range of values of solar radiation (cal $/ \mathrm{cm}^{2}$ day).

It follows from the results of that investigation that $\mathrm{L}_{\text {opt }}$ will vary with solar radiation throughout the season, and that $L$ must be kept as close as possible to $L_{o p t}$ if the highest productivity is to be achieved. If $\mathrm{L}$ fails to adjust to the changes in solar radiation, productivity will fall, to an extent determined by the departure of $L$ from $\mathrm{L}_{\mathrm{opt}}$. In pasture swards $\mathrm{L}$ can be maintained near $\mathrm{L}_{\mathrm{opt}}$ by careful control of grazing or cutting, but in other crops, excepting those where thinning can be carried out, a compromise must be made between low $\mathrm{L}$ at the beginning of the season and high $\mathrm{L}$ at the end, so that the mean departure of $\mathrm{L}$ from $\mathrm{L}_{\mathrm{opt}}$ is minimal.

\section{The interpretation of nutritional experiments}

The results of experiments into the effect of other limiting factors must be interpreted against this background of the controlling influence of solar radiation on yield. As an example of this, a simple hypothetical experiment into the yield of a pasture sward may be taken. Let us assume that there are to be two treatments, $A$, in which a mineral element is added and $\mathrm{B}$, the control, growing without the addition of this element, and that pasture cuts are taken on several occasions during the growing season for the measurement of dry weight and productivity. In the early stages of growth, the removal of the nutrient restriction will result in an increase in leaf growth in treatment $A$ and hence to increased $L$. Greater absorption of solar radiation 
leads to increased productivity so that the observed difference between the treatments will be real, and readily explainable at this level of analysis. If, however, the swards are allowed to grow further before yield is measured, it may well be that $\mathrm{L}$ of the control is at or is still below $\mathrm{L}_{\text {opt }}$ while that of the treatment plots is above $\mathrm{L}_{\text {opt }}$. In these circumstances, the productivity of the treated swards has begun to fall and a smaller increase resulting from the treatment-or perhaps even no increase at allwill be demonstrated. This failure to show a response to the treatment is clearly an artifact in the interpretation, since the effects are confounded with the effects of high $\mathrm{L}$ on growth rate. Very late in the season, $\mathrm{L}$ in treatment $\mathrm{A}$ may be far in excess of $\mathrm{L}_{\text {opt }}$ and in the control swards may be at or just above $\mathrm{L}_{\text {opt }}$. In this event productivity may be less in the treated plots than in the control. Clearly, the response to an added nutrient interacts with the network of relationships of Fig. $I$ and unless this is taken into account the interpretation of results of such experiments is difficult and even hazardous. It may even be suggested that only when both treatments are compared at $\mathrm{L}_{\mathrm{opt}}$ can certainty be reached. Ideally it would be desirable to establish the curves of $\mathrm{C}$ on $\mathrm{L}$ for any one particular value of solar radiation, for each nutrient treatment added. As far as I am aware, the only fertilizer experimentation in which $\mathrm{L}_{\mathrm{opt}}$ is taken into account is Harper's ( $\mathrm{r}_{963}$ ) studies of the potato crop.

It may indeed be possible that the addition of a nutrient element alters the $\mathrm{C}: \mathrm{L}$ relationship, thereby complicating still further the interpretation of an apparently simple experiment. It might, for instance, increase $C_{\max }$ while leaving Lopt unchanged. Alternatively, a higher $\mathrm{L}_{\mathrm{opt}}$ might be found at the same $\mathrm{C}_{\max }$, or both $\mathrm{C}_{\max }$ and $\mathrm{L}_{\mathrm{opt}}$ might change. It is not difficult to envisage further possibilities. Furthermore, the incorporation of two or more varieties or species may increase the complexity of the situation; it is known from some of my (unpublished) work that two varieties of subterranean clover have different values of $\mathrm{L}_{\text {opt }}$ and $\mathrm{C}_{\max }$ when growing side by side. Their growth rates can clearly be compared only at $\mathrm{L}_{\text {opt }}$ and it is necessary to determine the shape of the $\mathrm{C}: \mathrm{L}$ relationship before a valid comparison can be attempted. At the moment, our knowledge of the effects of, say, nutrient applications on $\mathrm{C}_{\max }$ and $\mathrm{L}_{\mathrm{opt}}$ is so fragmentary that it is almost impossible to forecast what picture might emerge from a full experimental analysis along the lines suggested, and such data on leaf growth as are relevant (see Watson, 1952) are not sufficient to permit useful speculation.

\section{Summary}

This paper reviews the evidence which shows that, in the absence of other limiting factors, the productivity of crops is determined by the amount of solar energy available. Four papers in support of this contention are examined in detail. The complex interrelationship of crop growth rate, leaf area index (i.e. the ratio of leaf area to ground surface area) and solar energy is discussed. The need to interpret the results of fertilizer and other experiments against this background of interrelationships is stressed, since unless this is taken into consideration erroneous conclusions may be drawn. 


\title{
REFERENCES
}

Black, J. N. (1963). Aust. F. agric. Res. 14, 20.

Black, J. N. \& Watson, D. J. (I960). Field Crop Abstr. 13, I69.

Blackman, G. E. \& Black, J. N. (1959). Ann. Bot. NS 23, I3I.

Bonner, J. (1962). Science, ז37, I1.

Borden, R. J. (I945). Hawaii. Plant. Rec. 49, 259.

Boysen Jensen, P. (1932). Die Stoffproduktion der Pflanzen. Jena: G. Fischer Verlag.

Brougham, R. W. (1956). Aust. F. agric. Res. 7, 377.

Davidson, J. L. \& Donald, C. M. (1958). Aust. F. agric. Res. 9, 53.

Donald, C. M. (1951). Aust. F. agric. Res. 2, 355.

Donald, C. M. \& Black, J. N. (1958). Herb. Abstr. 28, 1.

Harper, P. (1963). Nature, Lond., 197, 917.

Kanda, M. \& Sato, F. (1963). Sci. Rep. Res. Inst. Tohoku Univ. Ser. D, 14, 57.

Loomis, R. S. \& Williams, W. A. (1963). Crop Sci. 3, 67.

Monsi, M. \& Saeki, T. (1953). Fap. F. Bot. 14, 22.

Nichiporovich, A. A. (1954). Photosynthesis and the Theory of Obtaining High Crop Yields. (In Russian). Moscow: USSR Academy of Sciences.

Penman, H. L. (1958). In The Biological Productivity of Britain, p. 9I. [W. B. Yapp and D. J. Watson, editors.] London: The Institute of Biology.

Rees, A. R. (1 963). Nature, Lond., r97, 63.

Stern, W. R. \& Donald, C. M. (1961). Nature, Lond., 189, 597.

Takeda, T. (I96r). fap. f. Bot. I7, 403.

Watson, D. J. (1947). Ann. Bot. NS II, 4I.

Watson, D. J. (1952). Advanc. Agron. 4, ror.

Watson, D. J. (I958). Ann. Bot. NS 22, 37.

\section{Irrigation as a factor in boosting food and fibre production}

\author{
By H. Olivier, Sir Alexander Gibb and Partners, Telford House, London, SW r
}

\section{Introduction}

Irrigation is an ancient practice dating back to before the dawn of history. Egypt claims to have the oldest dam, built 5000 years ago, to store water for drinking and irrigation. Indications are that sophisticated irrigation schemes existed in the lower Euphrates Valley 4000-6000 years ago. Wells, tanks and inundation canals were sources of irrigation in China, India and Pakistan thousands of years ago.

The industrial revolution of Europe was basically responsible for the great upsurge of irrigation developments during the nineteenth century when it is estimated that world irrigated areas increased from 20 million to 100 million acres (Gulhati, I958). New inventions, discoveries, mechanization and improved communications resulted in great redistributions of population: from rural to urban areas and from country to country. The effects of recurring droughts and famines on populations depending on rain or river-flood agriculture were observed, reported, and interpreted and there followed an increasing awareness of the meaning of the term 'relative standards of living'. 'The new tools of science were applied to the agricultural sector and to the conception and construction of large-scale perennial irrigation schemes such as the classic projects of Egypt, India, Pakistan and Iraq. The agricultural sector began to develop its own industrial 'wing' by the production of fibre (cash) crops as distinct from food (subsistence) crops. 